\title{
Ensino de bioética na graduação de medicina: relato de experiência
}

Josimário Silva ${ }^{1}$, Helena Maria Carneiro Leão ${ }^{2}$, Amanda Cristina de Andrade Costa Pereira ${ }^{3}$

\section{Resumo}

O ensino da bioética vem se revelando ferramenta essencial na formação do futuro médico, tendo em vista que pode propiciar o despertar de nova sensibilidade na tomada de decisão em procedimentos que irão definir, muitas vezes, o limite entre vida e morte, entre sofrer e aliviar o sofrimento. Este trabalho discorre sobre a aplicação de metodologia de ensino de bioética em curso de medicina, buscando enfatizar nova abordagem entre pessoas em situação antagônica - médicos e pacientes -, dotando os primeiros a adotar o princípio da solidariedade no cotidiano profissional, considerando especialmente que se vive em uma sociedade que necessita se tornar fraterna.

Palavras-chave: Ética. Bioética. Educação médica.

\section{Resumen}

\section{Enseñanza de la bioética en la graduación de medicina: relato de experiencia}

La enseñanza de la bioética se ha revelado una herramienta de gran relevancia en la formación del futuro médico, dado que puede proporcionar el despertar una nueva conciencia en la toma de decisiones que van a definir, muchas veces, el límite entre vida y muerte, entre sufrir y el alivio del sufrimiento. Este estudio discursa acerca de la aplicación de una metodología de enseñanza de la bioética en el curso de medicina que busca destacar un nuevo enfoque en la relación entre personas en situación antagónica - médicos y pacientes Facilitando a los primeros a adoptar el principio de la solidaridad en el cotidiano profesional, considerando sobre todo que se vive en una sociedad que se hace necesario volverse fraterna.

Palabras-clave: Ética. Bioética. Educación médica.

\begin{abstract}
Teaching bioethics in a medical science graduation: experience report

Bioethics is becoming a great relevancy instrument in graduating future doctors, considering that it may awake new awareness of decision making, which may determine the limit between life and death, suffering and being relieved. This work discusses bioethics methodology in the medicine course that emphasizes a new approach between people in antagonistic situation - doctors and patients - to our daily days the principle of solidarity, ones that society needs to become fraternal.

Key words: Ethics. Bioethics. Medical education.
\end{abstract}

1. Doutor josimario.bioetica@gmail.com 2. Doutoranda helenacleao@hotmail.com 3.Graduanda acac.pereira@gmail.com Universidade Federal de Pernambuco (UFPE), Recife/PE, Brasil

Correspondência

Josimário Silva - Rua Conselheiro Portela, 565/201 CEP 52020-030. Recife/PE, Brasil.

Declaram não haver conflito de interesse. 
Educar é com certeza uma das mais difíceis tarefas na construção social de uma nação. No mais das vezes, o educador tem a tendência natural de ensinar de acordo com a sua percepção e valores, processo em que a transmissão do conhecimento não dá espaço à existência de diálogo mais aberto e reflexivo entre educando e educador. Mas educar é acima de tudo não dogmatizar. E aí reside o grande desafio do educador: como educar sem imprimir seus dogmas ao educando ${ }^{1}$.

Primeiramente, os educadores devem perceber que houve mudanças no processo ensinoaprendizado, e que aquilo que era unilateral, centrado na figura do educador, passou a ser dinâmico, cabendo ao aluno buscar a solução dos problemas e, ao professor, orientá-lo e ajudá-lo a superar dificuldades e limitações. Sendo assim, devem manter compromissos pessoais, morais e sociais que lhes acarretam responsabilidades técnicas e éticas. $\mathrm{Na}$ área médica acrescenta-se, ainda, o caráter altruísta, de solidariedade, ajuda e proteção que deve estar presente na relação pedagógica e na conduta médica. É importante estabelecer essa relação sem paternalismo, pois essa conduta restringe a capacidade de autonomia, podendo fragilizar o processo formativo diante das inúmeras situações e angústias que surgirão no cotidiano clínico ${ }^{2}$.

O conhecimento é um processo de construção contínuo e permanente, no qual os interlocutores devem estar sempre sensíveis às mudanças na ciência. Não se pode esquecer que a fundamentação da medicina está nas ciências biológicas, mas também nas humanas e sociais. Outro grande desafio do educador na área médica é sintonizar o ensino às exigências contemporâneas (alta tecnologia, grande volume de informação, elevado padrão de expectativa de atendimento, discrepância social no acesso aos serviços de saúde e aos direitos civis), enfatizando seu papel social ${ }^{3}$.

Atualmente, a formação médica, desde o início, vem primando pela técnica, pelo uso da tecnologia na resolução de todos os problemas e falhas que o organismo possa apresentar ${ }^{3}$. Ensinamos a nossos alunos e residentes que a cura do paciente será atingida se forem tecnicamente competentes e utilizarem todos os recursos tecnológicos disponíveis, mas esquecemos de dizer que, assim como os seres humanos, as máquinas também falham e quando isso acontece, não ensinamos a estabelecer diálogo franco e aberto com o paciente. É quando surge a indiferença, o medo, a omissão e a pouca habilidade em lidar com os aspectos mais básicos da relação médico-paciente ${ }^{4}$.
A introdução da bioética nos cursos de graduação médica abre nova perspectiva na formação do futuro profissional. Como se posicionar ante dilemas e conflitos no cotidiano médico quando estamos diante de diferentes moralidades? Como aceitar a pluralidade de opinião e valores nas intervenções em saúde? Observamos o impacto que temas como aborto, eutanásia, direito de decidir, direito de escolha etc. causam nos estudantes, ávidos pelas disciplinas práticas e estágios. Aquele falso universo de onipotência que culturalmente se instalou na cabeça de muitos estudantes começa a ruir, levando-os a perceber o quanto estão fragilizados diante da possibilidade de ter que decidir por outra pessoa, doente, vulnerável e que muitas vezes não consegue dimensionar os riscos agregados a sua doença. Não é simples tomar decisões no contexto médico, principalmente quando estão em jogo valores morais distintos.

A medicina contemporânea vem, por um lado, promovendo e intensificando o modelo tecnicista, que cada vez mais cedo traz inúmeros avanços na cura de doenças, no diagnóstico precoce e nas intervenções terapêuticas; por outro, essa mesma medicina vem provocando a necessidade de se repensar o modelo de relação médico-paciente. É de se questionar a dicotomia decorrente desse avanço, que não está influenciando na aceitação de certos parâmetros até então alheios ao universo científico, como a espiritualidade e outros aspectos culturais inerentes aos seres humanos ${ }^{5}$.

Em uma sociedade de direitos e deveres, cabe ao profissional entender a capacidade de deliberar do paciente e a responsabilidade de orientar e ajudar para que a deliberação atenda o real interesse do indivíduo que, na sua vulnerabilidade, encontra-se fragilizado para a tomada de decisão mais coerente com relação ao seu quadro clínico ${ }^{6}$ Mas como ensinar ética no curso médico se ainda existem pensamentos doutrinadores que não permitem estabelecer diálogo nas atividades acadêmicas? Como ensinar o estudante a ter postura ética senão Ihe dando a liberdade de fazer reflexões críticas, tornando-se, a partir disso, aliado a um modelo pedagógico participativo, em que todos os atores são responsáveis pela formação?

A ética hipocrática, ainda tão presente na formação profissional, deve ser contextualizada em perspectiva inédita, haja vista que novos dilemas e conflitos se estabeleceram nas relações em medicina ${ }^{3}$. Esse modelo, também denominado consequencialista ou sacerdotal, coloca o profissional de saúde em posição paternalista em relação ao pa- 
ciente, na qual, em nome do princípio da beneficência, são tomadas todas as decisões, desconsiderando seus desejos, crenças e opiniões ${ }^{3}$. Esse processo é de baixo envolvimento e tem como base a relação assimétrica de poder entre o médico e o paciente ${ }^{7}$.

Mas como ensinar ao estudante que a conduta moral mais adequada a reger a relação médicopaciente é a da virtude? Buscar o justo equilíbrio entre a necessidade de intervenção e o direito de autonomia do paciente é o maior desafio da medicina contemporânea. A apreensão desse processo deve orientar a formação do estudante, sendo iniciado desde a sua entrada na faculdade. Respeitar e compreender a ambiguidade moral das decisões que enfrentam e não deixar de buscar o que é certo e bom em cada decisão é o cerne deste grande desafio.

$O$ ensino de ética e bioética no curso médico tem sido motivo de intensos debates nos últimos anos. Esse fato é motivado por mudanças que vêm ocorrendo nos campos social, cultural, econômico, tecnológico e político. Faz-se imperioso qualificar melhor a formação ética do profissional médico, por ser essencial em seu labor cotidiano, bem como no relacionamento com pacientes/familiares e a comunidade em geral. O século XXI solicita profissionais habilitados para tomar decisões prudentes frente aos dilemas morais relacionados à saúde humana ${ }^{8}$.

Em 1910, foi publicado o estudo "Medical Education in United States and Canadá. A Report to the Carnegie Foundation for the Advancement of Teaching". Conhecido como o Relatório Flexner (Flexner Report) ${ }^{9}$, apontava a realidade da medicina do início daquele século e propostas de mudança para que se chegasse à medicina científica da atualidade, o que acarretou distanciamento entre a medicina e a ética. A medicina científico-tecnológica prescindia de reflexões éticas, o que trouxe consequência ao ensino e à prática médica. Dois levantamentos realizados em 1985 e 1992 mostram a situação do ensino da ética nos cursos de graduação em medicina no Brasil e permitiram concluir pela implantação do conteúdo de bioética, considerando as características desta disciplina e as necessidades de formação acadêmica ${ }^{10}$.

Em função das mudanças sociais que vêm ocorrendo nos últimos anos, houve a necessidade de aprofundar o debate ético no tocante ao processo formativo, vez que atualmente se exige a inserção de modelos pedagógicos mais contextualizados às novas características da estrutura e da dinâmica social ${ }^{11}$. Consideram-se, ademais, neste processo de mudança social, as novas exigências do Sistema Único de Saúde (SUS), que implicam em substanciais diferenças no processo de formação profissional, enfatizando a necessidade de habilitar o educando a compreender a importância dos princípios éticos para o fortalecimento de legitimação do sistema na sociedade.

\section{Método}

Este trabalho descreve uma experiência em sala de aula a partir de mudança na estratégia metodológica com acadêmicos do terceiro período do curso de Medicina da Universidade Federal de Pernambuco (UFPE). Trata-se de pesquisa qualitativa fenomenológica, decorrente da implementação de metodologia de ensino.

Na pesquisa fenomenológica, a fala do observador relata a sua experiência, além de sinalizar o caminho metodológico percorrido em direção àquilo que Benjamin ${ }^{12}$ chama de narrativa. Quando a pesquisa qualitativa analisa uma atividade da ciência, visa retratar a realidade, considerando que esta não pode ser quantificada. Assim, esta ferramenta trabaIha com o universo de crenças, valores, significados e outros construtos profundos das relações que não podem ser reduzidos à simples operacionalização de variáveis mensuradas quantitativamente ${ }^{13}$.

O módulo Medicina, Sociedade e Ética é parte integrante do eixo de desenvolvimento pessoal do novo projeto pedagógico do curso médico da UFPE. Sua finalidade, no terceiro período de formação deste curso, é a de continuar contribuindo, de forma ascendente, para o aprendizado iniciado no primeiro e segundo períodos nas disciplinas "Medicina, Ética e Relações Humanas" e "A Construção do Processo de Conhecimento".

A adequação do módulo buscou trabalhar conteúdos e metodologia de forma a permitir ao estudante reflexão mais profunda em torno da leitura, problematização e sistematização de temáticas que dizem respeito à complexidade dos desafios às habilidades, atitudes e futuras práticas médicas em contexto social marcado pela diversidade em todos os âmbitos. A partir de instrumento elaborado pela coordenação do curso, foi realizada avaliação pelos discentes para identificar fragilidades e pontos positivos. Vários itens foram avaliados, como desempenho docente, tempo para estudar, infraestrutura e carga horária.

O objeto de estudo foi o módulo Medicina, Sociedade e Ética na área de conhecimento em bioética. A turma, composta por 76 estudantes, atribuiu nota média de 3,5 em escore de 0 a 10 . No questio- 
nário havia campo no qual os alunos descreviam sua percepção sobre as aulas. As falas sobre o módulo identificavam-no como "mal administrado", "desestimulante", "sem propósito". Percebia-se claramente, por meio da aplicação do instrumento, que não havia nos estudantes motivação com a metodologia adotada. $\mathrm{O}$ uso repetido dessas expressões evidenciava a "necessidade urgente de reformular" a metodologia.

Com o resultado em mãos, a coordenação do curso tinha pela frente o desafio de melhorar os aspectos negativos sinalizados na avaliação. A primeira iniciativa foi mudar a coordenação dos módulos que não foram bem avaliados no ranking, inclusive em bioética. Com relação a este módulo, o desafio foi alterar o cenário de pouca motivação por parte dos discentes.

\section{Resultados}

A partir dos resultados, modificou-se a metodologia. Foi adotada a metodologia ativa para a transmissão do conhecimento, buscando-se estimular o desenvolvimento de competências e habilidades a partir dos conteúdos. Temas relevantes da bioética foram inseridos na ementa da disciplina: dilemas éticos no processo da morte e o morrer; atenção ao paciente de cuidados paliativos; aborto; cirurgia de mudança de sexo e as questões éticas e legais envolvidas; testamento vital e as diretivas antecipadas de vontade; aspectos éticos em neonatologia; cirurgia bariátrica; métodos de fecundação assistida, entre outros.

Procurando diversificar as atividades pedagógicas foi inserida a utilização de filmes, seminários, dramatizações, debates, participação de convidados de áreas médicas e de diversas áreas do saber (promotores de Justiça, psicólogos, antropólogos, gestores de serviços de saúde etc.). Esses profissionais mostraram suas realidades e estabeleceram discussão ampliada e aprofundada, que provocou inusitada participação discente.

Outra iniciativa foi o Laboratório de Bioética, que tinha como maior objetivo promover debate dinâmico por meio de simpósios, filmes, oficinas. Como espaço que busca construir conhecimento, foi estabelecida parceria com a Rádio Cremepe, iniciativa do Conselho Regional de Medicina do Estado de Pernambuco (Cremepe), voltada a difundir temas de interesse à saúde para profissionais e comunidade. Dessa forma, todas as atividades do laboratório foram transmitidas diretamente pela rádio para profis- sionais e demais ouvintes. Os melhores seminários apresentados pelos estudantes eram transformados em atividades de inserção social, enfatizando o papel do estudante de medicina na dimensão coletiva.

No primeiro ano de adoção da metodologia, conseguiu-se elaborar uma cartilha que orienta a população quanto ao uso racional de medicamentos. Desenvolvida de modo lúdico e fácil compreensão, foi dirigida à população leiga e explica os riscos do uso incorreto de medicamentos ou da automedicação, e a importância da orientação médica. A cartilha foi distribuída em programas de atenção básica da rede de saúde vinculados ao curso médico da UFPE. Posteriormente, foi transcrita em braile, iniciativa importante para consolidar o processo de inclusão social de pessoas com deficiência visual, haja vista existir (em braile) bem poucas publicações de orientação quanto ao uso correto de medicamentos.

Outra iniciativa foi a Liga Acadêmica de Transplantes de Tecidose Órgãos de Pernambuco(Lattope), na qual os alunos foram capacitados em temas relacionados aos transplantes de órgãos e tecidos, desde a política nacional de transplantes até ao procedimento cirúrgico. Após a capacitação, os acadêmicos passaram à segunda fase do projeto: participar em campanhas de conscientização sobre a importância da doação de órgãos e tecidos pela sociedade. $\mathrm{Na}$ terceira e última fase do projeto, passaram a acompanhar cirurgias de transplantes e realizar plantões em hospitais captadores de órgãos, visando acompanhar protocolos de morte encefálica - projeto no qual destacamos a participação efetiva da Central de Transplantes de Pernambuco.

A elaboração de um Código de Ética do Estudante de Medicina foi outra ação iniciada no módulo bioética - da qual os acadêmicos participaram intensamente. Debates acalorados sobre a construção desse código e de suas normas regimentares contribuíram para que os estudantes não apenas debatessem os conflitos éticos da prática profissional, como também se familiarizassem com o Código de Ética Médica (CEM), que define os critérios deontológicos do exercício da medicina. Para essa atividade, o Cremepe deu o subsídio necessário à construção do instrumento. Foram várias estratégias adotadas, sempre buscando envolver o acadêmico no sentido de contextualizar a realidade clínica vivenciada por médicos na assistência.

Ao finalizar o módulo, foi realizada nova avaliação discente - avaliações essas que foram se repetindo ao longo de outras turmas. A avaliação associada à observação qualitativa mostrou a par- 
ticipação efetiva dos acadêmicos, com baixíssimo índice de absenteísmo nas aulas. Cabe ressaltar que a utilização da observação como técnica de pesquisa procurou analisar e/ou medir os eventos estudados sem empregar instrumental estatístico na análise dos dados, envolvendo apenas dados descritivos sobre pessoas, lugares e processos interativos a partir do contato direto do pesquisador com a situação estudada.

Assim, procurou-se compreender os fenômenos segundo a perspectiva dos sujeitos, ou seja, dos participantes da situação em estudo. Nesse sentido, destacam-se algumas falas em resposta ao questionamento da importância dos temas discutidos no módulo:

"Os temas discutidos são polêmicos, mas é imprescindivel que haja reflexão e discussão sobre eles. Foi importante para a minha formação perceber que a discussão é elemento fundamental na formação de uma sociedade mais ética" - Acadêmico;

"Totalmente relevante para a minha formação. Surpreendi-me com alguns temas porque passei a ter conhecimento de coisas que não sabia ou parei para refletir sobre diferentes aspectos. Nessa cadeira desenvolvi o raciocínio da ética médica nas atividades diárias às quais os médicos estão submetidos. É preciso pensar que suas ações terão consequências na vida de seres humanos e, portanto, estar preparado para arcar com suas responsabilidades, sendo íntegro, coerente é ético em suas decisões" - Acadêmica;

"Durante as apresentações e discussões, foram expostos várias vezes pontos de vista divergentes do meu. Entendo que em uma sociedade democrática não posso impor as minhas ideias a outrem, mas as defendo sustentando-as com argumentos" - Acadêmico.

Tanto pela observação quanto pelo resultado das avaliações, foi possível constatar maior motivação e interesse pelos conteúdos e estratégias adotadas, bem como maior interação e participação nas discussões e debates. De acordo com o instrumento avaliativo utilizado para que o aluno pudesse fazer as observações, ficou evidenciado que a participação de profissionais de diversas áreas do saber ampliou a visão do universo médico, contribuindo para a percepção das diferentes moralidades dos atores sociais que podem estar inseridos em determinada situação clínica.

No sentido de valorizar ainda mais as iniciativas dos estudantes e propiciar melhor aproveitamento das atividades elaboradas, muitas delas fo- ram transformadas em artigos científicos, trabalhos para congressos, manuais de orientação, elaboração de normativas e trabalhos sociais. 0 módulo passou a ser espaço de consultoria pelos discentes que já passaram pela disciplina, principalmente no que concerne às situações identificadas como dilemas e conflitos éticos. Pode-se dizer que surgiu nova percepção a respeito do módulo pelos discentes, que repercutiu em maior visibilidade também em relação aos demais módulos do curso médico.

\section{Considerações finais}

Durante muito tempo o ensino médico nas instituições públicas centrou-se no poder do professor. Os antigos catedráticos, que dominavam o conhecimento, não permitiam um fórum de discussão mais ampliado com os discentes. Nesse modelo vertical e unilateral, o estudante era o produto de uma visão muitas vezes impermeável, na qual não cabiam contra-argumentações. Com isso, o raciocínio crítico não tinha espaço - apesar de reconhecer que o modelo anteriormente adotado teve seu mérito ${ }^{2,3}$. Com a evolução dos modelos pedagógicos e a emergência de novas realidades sociais a práxis médica mudou, tornando indispensável admitir a necessidade de novas formas no ensino médico.

Entendemos, por conseguinte, que existe a necessidade de construir metodologia ativa, na qual docentes e discentes sejam parceiros na busca pelo conhecimento. Provocar os discentes para que entendam que o processo educativo é uma parceria, na qual desenvolver uma visão crítica sobre os dilemas e conflitos nas situações do cotidiano médico é o grande desafio em uma sociedade com valores morais tão plurais. Em decorrência, este é um dos nossos grandes objetivos ${ }^{1}$.

As reformas curriculares são necessárias para adequar a evolução do conhecimento e podem, sim, formar um bom médico. A inserção da bioética no modelo formativo provocou nos discentes maior participação nos debates, além de evidenciar a necessidade de ampliar sua percepção em relação à pessoa doente como agente de direitos e prerrogativas ${ }^{8,11}$. Disso se depreende que uma proposta de educação inserindo os atores sociais como agentes que legitimam a formação médica produz maior identidade com a comunidade e desenvolve o senso de cidadania ${ }^{1,5}$.

A experiência permitiu constatar que no modelo atual o papel do docente deve ser de transformador, promovendo ações indutoras que des- 
pertem novo olhar e interesse na construção coletiva do conhecimento. Esta sensibilidade não deve basear-se nas evidências científicas, mas agregar - acima de tudo - o entendimento do ser humano na sua pluralidade ${ }^{7,9}$. A metodologia adotada no módulo de bioética no curso médico da UFPE vem conseguindo sensibilizar os discentes no sentido de ampliar a visão para além do conteúdo dos livros, ressaltando também sua importância como agente de transformação social.

Nesse relato de experiência é descrita a trajetória adotada para desenvolver metodologia no ensino da bioética que promova transformação em relação à forma anterior de transmissão do conhecimento. $\mathrm{O}$ objetivo foi atingido à medida que as demais turmas que passam pelo módulo conseguem se identificar como agentes sociais dos inúmeros dilemas e conflitos éticos comuns nesse campo do conhecimento. O módulo possibilitou aos discentes participar diretamente na construção de um modelo que vai ao encontro de suas reais necessidades de formação no curso médico, dando-lhes liberdade de pensar e se expressar.

Como educadores, sabemos que esta experiência é apenas o começo de um processo que pretende estimular nova mentalidade na construção do conhecimento. Desde já observamos nitidamente que nesta transformação radical existe interesse por parte dos discentes. Devemos trazer a bioética para o cotidiano da prática clínica e, com isso, provocar nos discentes a necessidade de refletir nas tomadas de decisão profissional, bem como em sua atuação na dimensão social. A atuação em outros espaços de interação capacita o discente a compreender a ética de maneira mais ampla e profunda, contribuindo para a formação da reflexão cidadã. Ensinar pelo exemplo, mas permitir essa reflexão, favorece alcançar alternativas mais propícias à relação médico-paciente.

\section{Referências}

1. Freire P. Pedagogia da tolerância. São Paulo: Editora Unesp; 2005.

2. Junior SMSL. Ética do professor de medicina. Rev. bioét. (Impr.). 2002;10(1):49-84.

3. Silva JJ, organizador. Ética no contexto atual. Pernambuco: Editora Universitária UFPE; 2006.

4. Lown B. A arte perdida de curar. São Paulo: Peirópolis; 1996.

5. Clotet J, Feijó A, Oliveira MG, organizadores. Bioética: uma visão panorâmica. Porto Alegre: Edipucrs; 2005.

6. Mello Filho J. Identidade médica. São Paulo: Casa do Psicólogo; 2006.

7. Vieira TR, Diniz NM, Silva JJ. Bioética e construção da normatividade. In: Anjos MF, Siqueira JE, organizadores. Bioética no Brasil: tendências e perspectivas. São Paulo: Ideias Letras; 2007. p. 7093.

8. Francesconi CF, Goldin JR. Bioética clínica. In: Clotet J, Feijó A, Oliveira MG, organizadores. Op. cit. p. 59-83.

9. Flexner A. Medical education in the United States and Canada. New York: Carnegie Foundation for the Advancement of Teaching; 1910. (Bulletin, 4).

10. Siqueira JE. O ensino da ética no curso de medicina. Mundo Saúde (Impr.). 2009;33(1):8-20.

11. Almeida M, Feuerwerker L, Llanos M. A educação dos profissionais de saúde na América Latina: teoria e prática de um movimento de mudanças. São Paulo: Hucintec; 1999. 2 v.

12. Benjamin W. Magia e técnica, arte e política: ensaios sobre literatura e história da cultura. $7^{\mathrm{a}}$ ed. São Paulo: Brasiliense; 1994. (Obras Escolhidas; v. 1).

13. Godoy AS. Introdução à pesquisa qualitativa e suas possibilidades. Revista de Administração de Empresas. 1995;35(2):57-63.

\section{Participação dos autores}

Josimário Silva, coordenador do módulo, elaborou o artigo. Helena Leão colaborou na elaboração. Amanda Cristina Pereira colaborou na pesquisa de artigos relacionados, revisão dos textos e tradução para inglês e espanhol.

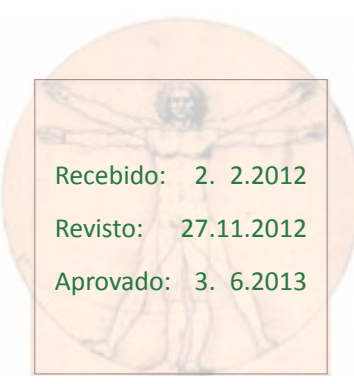

